\title{
Analgesic effect of preoperative versus intraoperative dexamethasone after laparoscopic cholecystectomy with multimodal analgesia
}

\author{
Se Hun Lim ${ }^{1}$, Eun Ho Jang ${ }^{1}$, Myoung-Hun Kim ${ }^{1}$, Kwangrae Cho ${ }^{1}$, Jeong Han Lee ${ }^{1}$, Kun Moo Lee ${ }^{1}$, \\ Soon Ho Cheong ${ }^{1,2}$, Young-Jae Kim ${ }^{1}$, and Chee-Mahn Shin ${ }^{1}$ \\ ${ }^{1}$ Department of Anesthesiology and Pain Medicine, Busan Paik Hospital, College of Medicine, Inje University, \\ ${ }^{2}$ Department of Paik Institute for Clinical Research, Inje University, Busan, Korea
}

Background: Pain after laparoscopy is multifactorial and different treatments have been proposed to provide pain relief. Multimodal analgesia is now recommended to prevent and treat post-laparoscopy pain. Dexamethasone is effective in reducing postoperative pain. The timing of steroid administration seems to be important. We evaluated the analgesic efficacy of preoperative intravenous dexamethasone 1 hour before versus during laparoscopic cholecystectomy with multimodal analgesia.

Methods: One hundred twenty patients aged 20 to 65 years old were allocated randomly into one of three groups ( $n=40$, in each). The patients in the group $\mathrm{N}$ received normal saline 1 hour before induction and after the resection of gall bladder. The patients in the group S1 received dexamethasone $8 \mathrm{mg} 1$ hour before induction and normal saline after the resection of gall bladder. The patients in the group S2 received normal saline 1 hour before induction and dexamethasone $8 \mathrm{mg}$ after the resection of gall bladder.

Results: VAS scores of group S1 and S2 were lower than that of group N during 48 hours after laparoscopic cholecystectomy. There were no significant differences of VAS scores between the group S1 and the group S2. The analgesic consumption of group S1 and S2 were significantly lower than that of group $\mathrm{N}$.

Conclusions: A single dose of dexamethasone $(8 \mathrm{mg})$ intravenously given 1 hour before induction or during operation was effective in reducing postoperative pain after laparoscopic cholecystectomy with multimodal analgesia. The analgesic efficacy of preoperative intravenous dexamethasone 1 hour before versus during surgery was not significantly different. (Korean J Anesthesiol 2011; 61: 315-319)

Key Words: Dexamethasone, Laparoscopic cholecystectomy, Postoperative pain.

Received: September 29, 2010. Revised: 1st, November 23, 2010; 2nd, January 5, 2011. Accepted: January 20, 2011.

Corresponding author: Se Hun Lim, M.D., Department of Anesthesiology and Pain Medicine, Paik Hospital, Gaegeum 2-dong, Busanjin-gu, Busan 614-735, Korea. Tel: 82-51-890-6520, Fax: 82-51-898-4216, E-mail: anespc@medimail.co.kr

ㄷ) This is an open-access article distributed under the terms of the Creative Commons Attribution Non-Commercial License (http:// creativecommons.org/licenses/by-nc/3.0/), which permits unrestricted non-commercial use, distribution, and reproduction in any medium, provided the original work is properly cited. 


\section{Introduction}

Laparoscopic cholecystectomy has beneficial effects compared to laparotomy such as a reduced hospitalization period, cost, and use of analgesic with improved lung capacity and arterial oxygen tension $[1,2]$. Nevertheless, the degree of pain on the first and second day after surgery is no different to laparotomy so the use of an effective analgesic is required $[1,3]$.

Pain after laparoscopy occurs for various reasons and a range of treatments have been suggested for the reduction in pain $[4,5]$. There are reports that local anesthesia saturation [6], removal of remaining carbon dioxide [4], administration of antiinflammatory analgesic before surgery [7], and dexamethasone [8] are effective in postoperative pain management. Recently multimodal analgesia methods, where a combination of the above methods is used, are recommended for their effectiveness [9].

It has been known that intravenous dexamethasone is more effective for the prevention of nausea and vomiting after surgery when administered after surgery rather than before [10]. However, the timing of intravenous dexamethasone injection for the purpose of pain relief is not clear yet $[8,11,12]$. The aim of this study was to investigate whether the timing of the administration of steroids affects postoperative pain management in patients undergoing multimodal analgesia after laparoscopic cholecystectomy.

\section{Materials and Methods}

This study was approved by the Ethics Committee and the research method was explained to the patients to obtain their written consent. One hundred and twenty patients who were grade 1 and 2 based on the ASA body classification scheduled for laparoscopic cholecystectomy under general anesthesia were included as subjects in this study. Patients with allergies or restrictions to NSAIDs, patients who had been continuously taking NSAIDs, patients had been administered narcotic analgesics before surgery, patients with a BMI over 30, diabetic patients, patients who switched to laparotomy during surgery, and patients who were taking medication for chronic pain were excluded from the study.

Subjects were randomly assigned to a control group (group $\mathrm{N})$, to a group who received $8 \mathrm{mg}$ dexamethasone $1-2$ hours before surgery (group S1), and to a group who received $8 \mathrm{mg}$ dexamethasone during surgery (group S2). There were no significant differences in sex ratio, age, weight, height, duration of surgery, and duration of anesthesia between the groups (Table 1).

In a visit before surgery, the notion of VAS (visual analog scale) was thoroughly explained $(0=$ no pain, $10=$ unimaginably severe pain). An hour before surgery, group S1 received $8 \mathrm{mg}$ of dexamethasone while group $\mathrm{N}$ and group $\mathrm{S} 2$ received the same amount of normal saline $(1.6 \mathrm{ml})$ as the preanesthetic administration by a nurse unaware of the research.

When the patients arrived in the operating room, an ECG, pulse oxygen monitor, and non-invasive automatic BPM were attached and the patients' states were monitored during surgery. $2 \mathrm{mg} / \mathrm{kg}$ of propofol was IV injected for the loss of consciousness, intubation was done after IV injection of $0.6 \mathrm{mg} /$ $\mathrm{kg}$ rocuronium bromide, and anesthesia was maintained with $1.5 \mathrm{~L} / \mathrm{min}$ of $\mathrm{O}_{2}, 1.5 \mathrm{~L} / \mathrm{min}$ of $\mathrm{N}_{2} \mathrm{O}$, and $1.5-2.5 \%$ of sevoflurane. Tidal volume and breathing rate were controlled to maintain a 35-40 mmHg end tidal $\mathrm{CO}_{2}$. All patients were IV injected with $30 \mathrm{mg}$ of ketorolac after intubation.

One surgeon fully experienced in laparoscopic cholecystectomy did all the surgeries the same. The operating table was adjusted for the patient to be in the $15-20^{\circ}$ trendelenburg position and $\mathrm{CO}_{2}$ gas was injected into the abdominal cavity through a Veress needle inserted into the incision below the belly button. After creating a state of pneumoperitoneum, the operation was done with the patient in an inverse trendelenburg position. To minimize hemodynamic effects, the abdominal pressure was maintained at $12 \mathrm{mmHg}$. The incision area was locally infiltrated with $3 \mathrm{ml}$ of $1 \%$ lidocaine before insertion of the Veress needle or Trocar. After confirming that the gall bladder was removed with the laparoscope, group S2 was IV injected with $8 \mathrm{mg}$ of dexamethasone while group $\mathrm{N}$ and group

Table 1. Demographic Data

\begin{tabular}{lccc}
\hline & Group N (n=40) & Group S1 (n=40) & Group S2 (n= 40) \\
\hline ASA status (1/2) & $27 / 13$ & $25 / 15$ & $26 / 14$ \\
Age (yr) & $47.5 \pm 13.5$ & $48.6 \pm 10.2$ & $49.5 \pm 10.2$ \\
Sex (M/F) & $25 / 15$ & $23 / 17$ & $22 / 18$ \\
Height (cm) & $166.7 \pm 7.8$ & $163.2 \pm 7.8$ & $162.1 \pm 8.4$ \\
Weight (kg) & $66.8 \pm 11.3$ & $65.5 \pm 10.2$ & $63.3 \pm 10.9$ \\
Duration of surgery (min) & $33.8 \pm 12.4$ & $30.8 \pm 8.6$ & $31.4 \pm 9.9$ \\
Duration of anesthesia (min) & $56.4 \pm 12.4$ & $53.9 \pm 8.2$ & $54.6 \pm 10.3$ \\
\hline
\end{tabular}

Values are mean \pm SD or number of patients. Group N: Normal saline, Group S1: dexamethasone 8 mg i.v. 1 hr before operation, Group S2: dexamethasone $8 \mathrm{mg}$ i.v. after gallbladder resection. ASA: American Society of Anesthesiologists, There are no significant differences among the groups. 
$\mathrm{S} 1$ received the same volume as normal saline (1.6 ml). After the surgery was completed, the operating surgeon pressed the patient's abdomen by hand to remove the remaining $\mathrm{CO}_{2}$ within the abdominal cavity before stitching up the skin incision. After the surgery, muscle relaxation was reversed with glycopyrrolate and pyridostigmine, and the patient was awakened.

An anesthesiologist with no knowledge of the patients' groups measured the degree of pain with VAS at 1, 3, 6, 24, and 48 hours after surgery based on the time the patient was moved to the recovery room. When the patient requested analgesic due to pain or the VAS was higher than 4, $30 \mathrm{mg}$ of ketorolac was IV injected first, and 30 minutes later if the VAS was still higher than 4, $50 \mathrm{mg}$ of tramadol was IV injected. When the pain continued, $50 \mathrm{mg}$ of meperidine was IM injected, and the amount of analgesic administered during the 48 hours after surgery was recorded. Patients were observed for complaints of nausea and vomiting for 24 hours after surgery, and when necessary, $4 \mathrm{mg}$ of ondansetron was IV injected.

Referring to Mentes et al. [13], the study was done on 40 patients in each group. All results were expressed as the mean \pm standard deviation. A one-way ANOVA was done for comparison of VAS between the control group (group N) and steroid group (groups S1 and S2) according to time, and a student t-test done for the comparison within the steroid group. A repeated measures ANOVA was done for the comparison analysis to test the treatment effect of steroids or the timing of the administration of steroids regarding the repeated measurements of VAS. A one-way ANOVA was done to compare the amount of ketorolac and tramadol administered to the control group and the 2 steroid groups. SAS Enterprize guide 4.1 (SAS Institute, Cary, NC) was used as a statistics program and

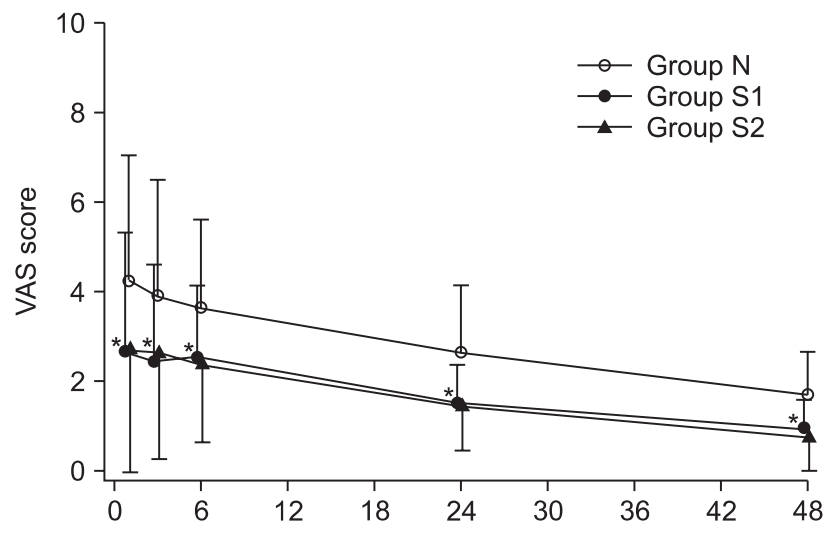

Fig. 1. Changes in postoperative pain among groups during perioperative periods. Patient's assessment of pain is described as VAS scores. Patients who received dexamethasone suffered significantly less pain during 48 hours after laparoscopic cholecystectomy. Group $\mathrm{N}$ : Normal saline, Group S1: steroid $8 \mathrm{mg}$ i.v. $1 \mathrm{hr}$ before operation, Group S2: steroid $8 \mathrm{mg}$ i.v. after gallbladder resection. ${ }^{*} \mathrm{P}<0.001$ one-way ANOVA among groups. the results were considered statistically significant when value the $\mathrm{P}$ was less than 0.05 .

\section{Results}

The VAS of groups S1 and S2 significantly decreased during 1, $3,6,24$, and 48 hours postoperatively compared to group N (Fig. 1). However, there was no significant difference in VAS between group S1 and S2 (Fig. 1). The repeated measures ANOVA analysis results regarding the repeat measurements of VAS also confirmed that steroid administration caused a significant decrease in VAS, and the difference according to the timing of the administration of the steroid was not observed (Fig. 1).

The amount of ketorolac and tramadol IV injected during the 48 hours postoperatively was significantly reduced in group S1 and group S2 compared to group N (Table 2). No groups required intramuscular injection of $50 \mathrm{mg}$ of meperidine for pain reduction after surgery. There were no patients in group S1 who complained of nausea or vomiting during the first 24 hours postoperatively, and 1 patient each in group $\mathrm{N}$ and group S2 complained of vomiting, but IV injection of ondansetron was not necessary.

Intravenous dexamethasone was very effective in the postoperative pain management of patients undergoing multimodal analgesic after laparoscopic cholecystectomy. There were no differences in the degree of pain or usage of analgesic between administering dexamethasone 1 hour before surgery or during surgery.

\section{Discussion}

After laparoscopic cholecystectomy, patients complain of pain from the incision of the skin, of visceral pain, and of shoulder pain from diaphragm stimulation [14]. Since pain is caused by various reasons, a range of treatment methods has been introduced for the reduction of pain $[4,5]$.

In the case of local anesthetic infiltration, there are various results according to research, and while local anesthetic infiltration in the incision area is the recommended pain manage-

Table 2. Analgesic Consumptions during 48 Hours after Laparoscopic Cholecystectomy

\begin{tabular}{lccr}
\hline & $\begin{array}{c}\text { Group N } \\
(\mathrm{n}=40)\end{array}$ & $\begin{array}{c}\text { Group S1 } \\
(\mathrm{n}=40)\end{array}$ & $\begin{array}{c}\text { Group S2 } \\
(\mathrm{n}=40)\end{array}$ \\
\hline Ketorolac (mg) & $51.0 \pm 33.1$ & $30.0 \pm 29.1^{*}$ & $25.2 \pm 29.1^{*}$ \\
Tramadol (mg) & $16.6 \pm 55$ & $6.5 \pm 17.5^{*}$ & $5.5 \pm 19.5^{*}$ \\
\hline
\end{tabular}

Values are mean \pm SD or number of patients. Group N: Normal saline, Group S1: steroid $8 \mathrm{mg}$ i.v. 1 hr before operation, Group S2: steroid $8 \mathrm{mg}$ i.v. after gallbladder resection. ${ }^{*} \mathrm{P}<0.001$ one-way ANOVA among groups. 
ment method in laparoscopic cholecystectomy, infusion of local anesthesia into the abdominal cavity is reported to be more effective in obstetrics and gynecology laparoscopy $[6,9,15]$. Non-steroidal anti-inflammatory drugs are recommended to be used before surgery, before anesthesia, or even during surgery, and for 3-4 days after surgery [9]. There are also reports that the remaining $\mathrm{CO}_{2}$ in the abdominal cavity is related to the postoperative pain so thorough removal of the remaining $\mathrm{CO}_{2}$ is effective [4]. There are reports that dexamethasone is effective in pain reduction after laparoscopic cholecystectomy [8]. Recently however, a multimodal analgesic method, which combines and utilizes the above methods is recommended [9].

The mechanisms of the pain relief for the effects of dexamethasone are not clear yet, but the decrease in cyclooxygenase and lipoxygenase products by suppressing phospholipases in the periphery plays a major role $[16,17]$. Additionally, reduced bradykinin, which reinforces pain in the inflamed tissue and operated area, and the concentration of nerve proteins secreted from the periphery nerve system are involved in the pain relief effect $[18,19]$. In our study, when compared to the control group, the use of dexamethasone showed a significant decrease in VAS at 1, 3, 6, 24, and 48 hours postoperatively and a decrease in the use of analgesics. Bisgaard et al. [8] also reported similar results but were different to our study in that the VAS was not different to the control group at 24 hours postoperatively. The reason for this difference may be partially that Bisgaard et al. [8] prescribed NSAIDs at regular intervals even without pain after surgery, whereas in our study, the pain of the patients was assessed to prescribe NSAIDs.

Considering the fact that $1-2$ hours is needed for the onset of the medication, to reduce the inflammation response after surgery, the timing of the administration of the steroid before surgery is important [16]. Bisgaard et al. [8] reported that when $8 \mathrm{mg}$ of dexamethasone was IV injected 90 minutes before laparoscopic cholecystectomy, the postoperative pain and required amount of opioids were reduced approximately $50 \%$ compared to the placebo group. Elhakim et al. [11] reported that there was no pain relief effect when dexamethasone was IV injected directly before incision of the skin. However, in our study, there were no differences in the degree of pain and the required amount of analgesics when dexamethasone was IV injected during surgery compared to when it was administered 1 hour preoperatively. The reason for this difference between the 2 studies is thought to be from the differences in multimodal analgesic methods. Elhakim et al. [11] used infusion of local anesthesia into the abdominal cavity in combination, but since the pain relief effect of this method is not clear in laparoscopic cholecystectomy, its use is not generally recommended [9]. Our study used IV injection of NSAIDs when inducing anesthesia in combination, which is a recommended pain management method although the suitable dosages are in inconclusive [9]. In addition, the different purposes of the research, the differences in surgery time due to the expertise of the operating surgeon, and subjective characteristics of the patients responding to the pain could all be involved with the differences in results between the 2 studies, and thus, further research regarding this may be necessary.

Postoperatively or during chemotherapy, dexamethasone is used to reduce nausea and vomiting. Although the mechanism is not clear, it is thought to be due to the effect on the glucocorticoid receptors in the area of postrema and nucleus tractus solitaries [20-22]. Bisgaard et al. [8] reported that nausea or vomiting in patients who complained of them was significantly reduced when $8 \mathrm{mg}$ of dexamethasone was IV injected before surgery. According to Kim et al. [23], the effect of intravenous steroid injection on nausea and vomiting within 24 hours of surgery were different in relationship to age and was not effective for elderly patients. However, in our study, only 1 patient in each group complained of nausea or vomiting. The reason for this relatively low occurrence of nausea and vomiting could be unrelated to the IV injection of dexamethasone. Whereas Bisgaard et al. [8] used opioids to induce anesthesia and administered narcotic analgesic when necessary, our study limited the use of opioids to when pain that did not respond to NSAIDs occurred. Also the fact that the surgery time was relatively shorter than other studies may have contributed to these differences.

When steroids are used, complications such as delays in recovery, post-operative inflammation, glucose tolerance, and ulcers in the gastric mucous membrane can occur. Sauerland et al. [24] reported in their meta-analysis that there was no significant increase in complications when $15-30 \mathrm{mg} / \mathrm{kg}$ of methylprednisolone was used in one dose, and this is 50 times the amount of the $8 \mathrm{mg}$ of dexamethasone. In a metaanalysis regarding postoperative nausea and vomiting, one IV injection of dexamethasone did not increase the occurrence of inflammation or other complications [22]. In addition, in our study, there were no observations of complications related to dexamethasone.

Through this study, it could be concluded that intravenous injection of $8 \mathrm{mg}$ of dexamethasone can be helpful in the pain management of patients undergoing the multimodal analgesic method after laparoscopic cholecystectomy, and that the timing of the administration of the steroid did not affect postoperative pain management.

\section{Acknowledgements}

This work supported by the 2009 Inje University Research Grant. 


\section{References}

1. Joris J, Cigarini I, Legrand M, Jacquet N, De Groote D, Franchimont P, et al. Metabolic and respiratory changes after cholecystectomy performed via laparotomy or laparoscopy. Br J Anaesth 1992; 69: 341-5.

2. Grace PA, Quereshi A, Coleman J, Keane R, McEntee G, Broe P, et al. Reduced postoperative hospitalization after laparoscopic cholecystectomy. Br J Surg 1991; 78: 160-2.

3. Bisgaard T, Kehlet H, Rosenberg J. Pain and convalescence after laparoscopic cholecystectomy. Eur J Surg 2001; 167: 84-96.

4. Alexander JI. Pain after laparoscopy. Br J Anaesth 1997; 79: 369-78.

5. Wills VL, Hunt DR. Pain after laparoscopic cholecystectomy. Br J Surg 2000; 87: 273-84.

6. Lee IO, Kim SH, Kong MH, Lee MK, Kim NS, Choi YS, et al. Pain after laparoscopic cholecystectomy: the effect and timing of incisional and intraperitoneal bupivacaine. Can J Anaesth 2001; 48 : 545-50.

7. Joshi GP, Viscusi ER, Gan TJ, Minkowitz H, Cippolle M, Schuller R, et al. Effective treatment of laparoscopic cholecystectomy pain with intravenous followed by oral COX-2 specific inhibitor. Anesth Analg 2004; 98: 336-42.

8. Bisgaard T, Klarskov B, Kehlet H, Rosenberg J. Preoperative dexamethasone improves surgical outcome after laparoscopic cholecystectomy: a randomized double-blind placebo-controlled trial. Ann Surg 2003; 238: 651-60.

9. Bisgaard T. Analgesic treatment after laparoscopic cholecystectomy: a critical assessment of the evidence. Anesthesiology 2006; 104: 835-46.

10. Wang JJ, Ho ST, Tzeng JI, Tang CS. The effect of timing of dexamethasone administration on its efficacy as a prophylactic antiemetic for postoperative nausea and vomiting. Anesth Analg 2000; 91: 136-9.

11. Elhakim M, Nafie M, Mahmoud K, Atef A. Dexamethasone $8 \mathrm{mg}$ in combination with ondansetron $4 \mathrm{mg}$ appears to be the optimal dose for the prevention of nausea and vomiting after laparoscopic cholecystectomy. Can J Anaesth 2002; 49: 922-6.

12. Fujii Y, Itakura M. Reduction of postoperative nausea, vomiting, and analgesic requirement with dexamethasone for patients undergoing laparoscopic cholecystectomy. Surg Endosc 2010; 24: 692-6.

13. Mentes O, Harlak A, Yigit T, Balkan A, Balkan M, Cosar A, et al. Effect of intraoperative magnesium sulphate infusion on pain relief after laparoscopic cholecystectomy. Acta Anaesthesiol Scand 2008; 52: 1353-9.

14. Bisgaard T, Klarskov B, Rosenberg J, Kehlet H. Characteristics and prediction of early pain after laparoscopic cholecystectomy. Pain 2001; 90: 261-9.

15. Elhakim M, Elkott M, Ali NM, Tahoun HM. Intraperitoneal lidocaine for postoperative pain after laparoscopy. Acta Anaesthesiol Scand 2000; 44: 280-4.

16. Sapolsky RM, Romero LM, Munck AU. How do glucocorticoids influence stress responses? Integrating permissive, suppressive, stimulatory, and preparative actions. Endocr Rev 2000; 21: 55-89.

17. Callery MP. Preoperative steroids for laparoscopic surgery. Ann Surg 2003; 238: 661-2.

18. Hargreaves KM, Costello A. Glucocorticoids suppress levels of immunoreactive bradykinin in inflamed tissue as evaluated by microdialysis probes. Clin Pharmacol Ther 1990; 48: 168-78.

19. Hong D, Byers MR, Oswald RJ. Dexamethasone treatment reduces sensory neuropeptides and nerve sprouting reactions in injured teeth. Pain 1993; 55: 171-81.

20. Liu K, Hsu CC, Chia YY. Effect of dexamethasone on postoperative emesis and pain. Br J Anaesth 1998; 80: 85-6.

21. Rich WM, Abdulhayoglu G, DiSaia PJ. Methylprednisolone as an antiemetic during cancer chemotherapy--a pilot study. Gynecol Oncol 1980; 9: 193-8.

22. Henzi I, Walder B, Tramer MR. Dexamethasone for the prevention of postoperative nausea and vomiting: a quantitative systematic review. Anesth Analg 2000; 90: 186-94.

23. Kim HY, Lee MJ, Park PE, Koo JW. The effect of dexamethasone on postoperative pain and nausea and vomiting after laparoscopic cholecystectomy in younger and older patients. Korean J Anesthesiol 2008; 54: 651-5.

24. Sauerland S, Nagelschmidt M, Mallmann P, Neugebauer EA. Risks and benefits of preoperative high dose methylprednisolone in surgical patients: a systematic review. Drug Saf 2000; 23: 449-61. 